\title{
BIOLOGY, NATURE OF INFESTATION AND CONTROL OF THE APHID, APHIS GOSSYPII (GLOVER, 1877) (HEMIPTERA: APHIDIDAE) ON ARUM PLANT, COLOCASIA ESCULENTA
}

\author{
Murshida Begum*, Manogit Kumar Mandal, Md. Aminul Islam and \\ Moksed Ali Howlader \\ Department of Zoology, University of Dhaka, Dhaka-1000, Bangladesh
}

\begin{abstract}
An investigation was conducted for biology, nature of infestation and control of Aphis gossypii against cultivated arum plants Colocasia esculenta. Morphological characteristics of the adults and nymphs were observed by a compound microscope. The adults were quite variable in color (viz. whitish, yellowish, pale or dark green). The $4^{\text {th }}$ instar nymph and adults were almost equal in size $(0.22 \pm 0.005 \mathrm{~mm}$ long and $0.05 \pm 0.002 \mathrm{~mm}$ broad). The most important feature of the adults was a pair "cornicles" or "siphunculi. These were gregarious on the host leaves, the numbers varied from on average from 250 to 280 on leaves and 210 to 250 on peduncles of leaves during the study periods. The highest $62 \%$ aphids were controlled using hand crushing technique in the month of February, 2012. The average value recorded from untreated experiments in October 2011 compared to data found in each month from mechanically treated plants by t-tests were significantly different $(p<0.05)$. Mean of the each month data were compared with each other using Tukey's Honest Significance Difference (HSD) test, where, no values were significantly different each other $(p<0.05)$ except data from first spread leaf in January, 2012.
\end{abstract}

Key words: Aphis gossypii, Colocasia esculenta, infestation, mechanical control

\section{INTRODUCTION}

Aphis gossypii Glover (Hemiptera: Aphidae) is a cosmopolitan, polyphagous insect infesting over 900 plant species and are considered as a serious pest of the arum, Colocasia esculenta (Satar et al. 1999, Blackman and Eastrop 2000). The host plant belongs to the family Araceae under the kingdom Plantae of the order Alismatales. The life cycle of this pest, on the arum plant consists of three developmental stages, viz. the eggs, the nymphs, and the adults. The newly laid eggs are yellowish in color but they become soon shiny black. The eggs are deposited on the leaves and the peduncles of the plant (Sarwar 2014). The hatching of the eggs takes place soon after the laying of the eggs. The incubation period is recorded from $19-21$ hours. The bodies of the aphids are quite variable in color in different stages of their life (Granett et al. 2001).

This pest may transmit viruses from plant to plant on certain vegetables and ornamental plants (McGavin 1993). The viruses cause mottling, yellowing, or curling of leaves and stunting of plant growth. Although losses can be great,

*Author for correspondence: <murshida.begum@du.ac.bd>.

다일 2018 Zoological Society of Bangladesh DOI: http://dx.doi.org/10.3329/bjz.v46i1.37627 
they are difficult to prevent through the control of aphids because infection occurs even when their numbers are very low. It only takes a few minutes for the aphids to transmit the virus while it takes a much longer time to kill the aphid with an insecticide (Blackman 1994). A few aphid species attack parts of plants other than leaves and peduncles. Once aphid numbers are high and they have begun to distort curl leaves, it is often hard to control them because the curled leaves are lodging for aphids from insecticides or natural enemies (Conover 2009). Many aphid species prefer the undersides of leaves, so it is necessary to turn leaves over to check aphids. Monitoring is more effective to control the aphid in nature. Although, some researches have been done on biology, infestation on arum by aphids and their control in different countries, scanty of work is observed in Bangladesh. The main objectives of the present work was to study the biology of A. gossypii, to evaluate the nature of infestation of this pest on arum plants, C. esculenta and to determine the efficiency of mechanical control of the pest on the arum plant.

\section{MATERIAL AND METHODS}

Study sites: A plot for the culture of the host plant and observations of the infestations was maintained in a plant nursery garden at Uttara, Dhaka. Some experiments were carried out in the entomology laboratory of the Dhaka University.

Biology and infestation pattern: The arum plants, C. esculenta were grown in plant pots of fertile soil at Uttara in Dhaka. The experimental plants were started to culture in the pots on September 10, 2011. The plants were ready for natural infestation of aphids by September 27, 2011. Twenty four pots were placed in four plots, where one plot consists of six pots. Fifty centimeter diameter sized pots was filled with nourishing soils. The plants were sprinkled with water once in the morning and once in the afternoon. The first presence of nymphs of the aphids was recorded on 5th October, 2011. From this date the abundance of aphids were recorded for five consecutive days from 5th October to 9th October, 2011 as untreated experiment (Table 2). The records were maintained on the mean adults per square centimeter of leaves and the peduncle of leaves using plastic grid. A grid of $1 \mathrm{~cm}^{2}$ each was engraved on a plastic plate containing $10 \times 6$ cells for counting the number of aphids on the leaves and the peduncles of the host plant. The plants were observed at regular intervals to record the increase in the number of aphids.

The egg, nymph and adults of A. gossypii Glover were collected from the experimental plant and stored in plastic vials containing $70 \%$ alcohol for the 
study of biology. Several temporary slides of different life cycle stages of this insect were prepared using eosin dye at the histological laboratory in the Department of Zoology, University of Dhaka. Nymphal and adults body lengths and widths were measured using an ocular micrometer under a stereoscopic microscope (Meiji SKT-3BT) Photographs of all stages of life cycle were taken using a Nikon $\mathrm{F}_{60}$ camera under a compound microscope with light (Humascope Classic 2006/95/EC). Nymphs and adults were not separated during the study of infestation period.

Mechanical control: When population of the aphids reached a maximum level on most of the plants under the study, cluster of aphids were killed by hand crushing using a thin glove between the thumb and the forefingers of the right hand and holding the infested leaf with the left hand. The effects of the mechanical control treatment on the reduction of the aphids were observed by counting the number of aphids present on the leaves after 24 hrs of treatment. Hand crushing measures was applied two times in a week for the rolled leaf, 1st spread leaf and 2nd spread leaf. Nymphs and adults could not be possible to isolate during this trial. After starting the mechanical control method, the infestation pattern was recorded in weekly basis from October, 2011 to February, 2012. The average value recorded from untreated experiments in October, 2011 compared to data found in each month from mechanically treated plants by t-test. Mean of the each of the months were compared with each other using Tukey's Honest Significance Difference (HSD) test (Tukey 1949)

\section{RESULTS AND DISCUSSION}

Biology: The study showed that Aphis gossypii has three developmental stages throughout their life, i.e. the egg, the nymph and the adult. The newly laid eggs were elongated in shape with smooth surface and translucent and were yellow in color but soon became shiny black. They were deposited on the leaves and the peduncles of the arum plant, C. esculenta. Each egg was covered with wax secreted by the oviparae and laid singly in loose masses on the lower surface of the leaves. The hatching of the eggs occurred soon after the laying of the eggs. The incubation period in the laboratory was $19 \pm 0.3$ hours. The average nymphal period was $7 \pm 1$ days. The first instar nymphs were measured as $0.16 \pm 0.007 \mathrm{~mm}$ in length and $0.03 \pm 0.002 \mathrm{~mm}$ in width (Table 1). These were yellowish in color and transparent and after one day they turned grayish and elongated in shape. The compound eyes were oval, very conspicuous and red in color. The two antennae were prominent. The legs were not well developed and the thoracic segments were not markedly differentiated from each other and abdomen was relatively small and nine segmented (Fig. 1b). The nymphs of 
second instar were measured as $0.19 \pm 0.004 \mathrm{~mm}$ in length and $0.04 \pm 0.002$ $\mathrm{mm}$ in width (Table 1). They were structurally similar to the developed first instar but very sluggish, moved slowly around the host leaves. Thoracic regions were distinctly separated from each other (Fig 1c). The third instar nymphs were measured $0.21 \pm 0.005 \mathrm{~mm}$ in length and $0.05 \pm 0.002 \mathrm{~mm}$ in width (Table 1). The general body was yellow except the ventral surface which was pale. The antenna was prominent and eyes were red. Prominent wings pad were present. Two black spot were situated on the vertex and two round black spot $\mathrm{s}$ on the meta-notum. In the abdomen, sub dorsal stripes were brown and the mid dorsum was yellow (Fig. 1d). The fourth instar nymphs were measured as $0.22 \pm$ $0.005 \mathrm{~mm}$ in length and $0.05 \pm 0.002 \mathrm{~mm}$ in width (Table 1). The bodies were dark in color due to presence of wax secretions. The compound eyes were dark red. The rudimentary wings were quite distinct. The prothorax and mesothorax

Table 1. Size of different nymphal stages and adults of $A$. gossypii, collected from the experimental host plant, Colocasia esculenta grown at $19.82 \pm 4^{\circ} \mathrm{C}$ and $83 \pm 5 \% \mathrm{RH}$

\begin{tabular}{lcc}
\hline \multicolumn{1}{c}{ Stages } & Length $(\mathrm{mm})$ & Width $(\mathrm{mm})$ \\
\hline First instar nymph & $0.16 \pm 0.007$ & $0.03 \pm 0.002$ \\
Second instar nymph & $0.19 \pm 0.004$ & $0.04 \pm 0.002$ \\
Third instar nymph & $0.21 \pm 0.005$ & $0.05 \pm 0.002$ \\
Fourth instar nymph & $0.22 \pm 0.005$ & $0.05 \pm 0.002$ \\
Adults & $0.22 \pm 0.005$ & $0.05 \pm 0.002$ \\
\hline
\end{tabular}

were clearly separated and the abdomen was more elongated than thorax (Fig. 1e). Lastly the adults were measured from $0.22 \pm 0.005 \mathrm{~mm}$ in length and $0.05 \pm 0.002 \mathrm{~mm}$ in width (Table 1). The adults were quite variable in color. The most common (90\%) ones were pale green and the others were whitish, yellowish, or dark green in color. They feed themselves through sucking mouth parts called stylets, enclosed in a sheath called rostrum. The legs were pale with the tips of tibiae and tarsi black. The size of adults was similar to nymphs. The aphids have a pair "cornicles" or "siphunculi"and abdominal tubes and they were black in color. The adult have a tail-like protrusion called a "cauda" above their rectal apertures. Head and thorax were black and abdomen was yellowish green except for the tip of the abdomen that was darker. The egg-laying females were dark pinkish green and the males were similar (Fig. 1f). The duration of reproductive period of the adults was about 15 days and the post reproductive period was about 5 days. These values varied considerably with the changes in temperatures.

Infestation pattern: The first presence of nymph of the aphids was recorded on $5^{\text {th }}$ October. From this date the abundance of the aphids was recorded for five 
consecutive days. On the $5^{\text {th }}$ day the abundance of the aphids reached to such level that the both lower and upper surface of leaves and the peduncles were almost encrusted by the aphids. The records of five days of sampling were shown in Table 2 . The numbers of adults on leaves were increased by 12 percent in five days and 19 percent on peduncles. Host plants suffered severely, damage developing black spots on leaves, early senescence of leaves and peduncles, stunting of growth which leads to the death.
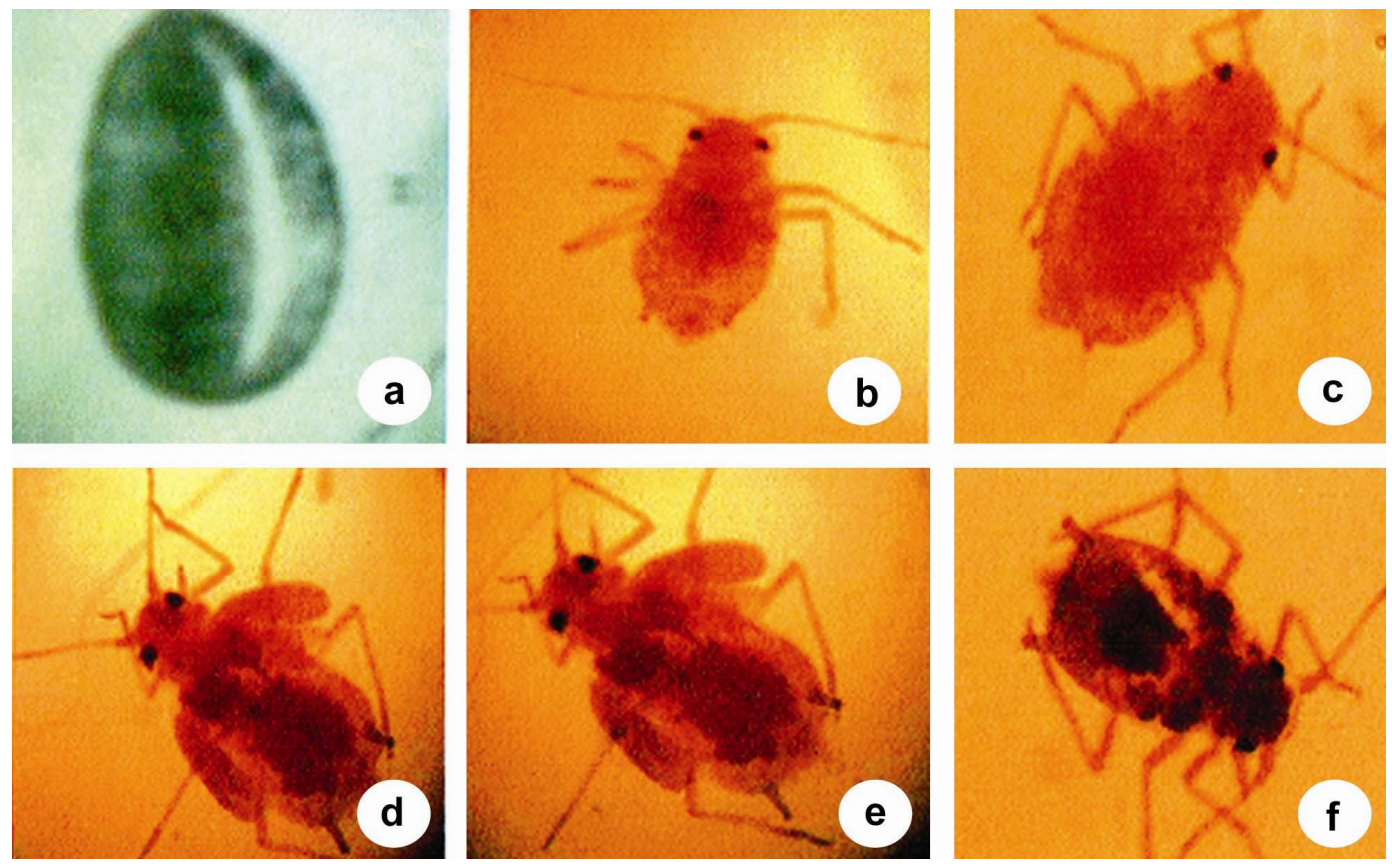

Fig. 1. Developmental stages of the aphid, A. gossypii Glover. (a). The eggs. (b) The first instar nymph. (c) The second instar nymph. (d) The third instar nymph. (e) The fourth instar nymph and (f) The adult.

Mechanical control: After sampling on the $5^{\text {th }}$ day, the mechanical control techniques of the aphids were applied in the treatment plots. The average number of nymphs and adults were recorded in each month from October, 2011 to February, 2012 were significantly different from the untreated ones found in October, 2011 ( $\mathrm{p}<0.05$ ) (Table 3). Mean number of aphids found in each month from October, 2011 to February, 2012 were not significantly different each other ( $\mathrm{p}<0.05$ ) except data from first spread leaf in January 2012 (Table 3). The highest $62 \%$ aphids were controlled in the month of February, 2012 (Table 3). Although the members were significantly increased during the month from December to February their effects on the growth and the 
appearance on the host plants were not visible. On the untreated host plants, the abundance of the aphids was quite higher on different parts of the host plants (Table 2). Due to the continuous infestations, the growth of the plants were stunted, the leaves senescent earlier and ultimate turned yellow. Some leaves developed, scattered black and yellow spots and finally most low leaves were dried up.

Table 2. Infestation pattern of untreated aphid, $A$. gossypii on different parts of arum plants, $C$. esculenta during the experimental period at $19.50 \pm 4^{\circ} \mathrm{C}$ and $84 \pm 5 \% \mathrm{RH}$

\begin{tabular}{lcc}
\hline Days & $\begin{array}{c}\text { No. of aphids on } \\
\text { leaves } / \mathrm{cm}^{2}\end{array}$ & $\begin{array}{c}\text { No. of aphids on } \\
\text { peduncles } / \mathrm{cm}^{2}\end{array}$ \\
\hline 1 & $250 \pm 5$ & $210 \pm 3$ \\
2 & $252 \pm 6$ & $215 \pm 7$ \\
3 & $260 \pm 5$ & $219 \pm 5$ \\
4 & $270 \pm 4$ & $230 \pm 4$ \\
5 & $280 \pm 7$ & $250 \pm 6$ \\
\hline
\end{tabular}

The means were calculated from 10 samples $(n=10)$ each day for 5 days.

Table 3. Distribution patterns of $A$. gossypii on different parts of the mechanically treated host plant, $C$. esculenta leaf during the whole experimental periods. Data were collected 24 hours after each treatment

\begin{tabular}{lcccc}
\hline \multirow{2}{*}{ Months } & \multicolumn{4}{c}{ Number of aphids/cm ${ }^{2}$} \\
\cline { 2 - 5 } & Rolled leaf & First spread leaf & Second spread leaf & Peduncles \\
\hline October 2011 & $122 \pm 1.81 \mathrm{a}$ & $115 \pm 1.52 \mathrm{a}$ & $105 \pm 3.51 \mathrm{a}$ & $90+4.85 \mathrm{a}$ \\
November 2011 & $125 \pm 2.35 \mathrm{a}$ & $116 \pm 2.13 \mathrm{a}$ & $110+3.26 \mathrm{a}$ & $85 \pm 4.65 \mathrm{a}$ \\
December 2011 & $120 \pm 2.65 \mathrm{a}$ & $110 \pm 2.45 \mathrm{a}$ & $108 \pm 4.41 \mathrm{a}$ & $95 \pm 3.95 \mathrm{a}$ \\
January 2012 & $125 \pm 3.21 \mathrm{a}$ & $120 \pm 3.19 \mathrm{~b}$ & $105 \pm 4.09 \mathrm{a}$ & $90 \pm 3.97 \mathrm{a}$ \\
February 2012 & $122 \pm 3.24 \mathrm{a}$ & $112 \pm 3.18 \mathrm{a}$ & $106 \pm 4.13 \mathrm{a}$ & $95 \pm 4.92 \mathrm{a}$ \\
\hline
\end{tabular}

*The mean of each month contains the data of four samples $(n=4)$ except the month of October, 2011 where the mean contains the data of three samples ( $\mathrm{n}=$ 3). The same letters against the means showed no significance difference ( $\mathrm{p}<$ 0.05). The means were separated for significant using a Tukey's HSD test.

Present studies revealed that A. gossypii heavily infest the arum plants, $C$. esculenta in Dhaka, Bangladesh. The life cycle of the aphids was completely depended on the host plant. The life cycle stages included the eggs, the nymphs and the adults as studied by previous worker (Picker et al. 2002). Picker et al. (2002) also determined the average adult body length of $A$. gossypii was $1.5 \mathrm{~mm}$. Some other workers measured the average length of the A. gossypii was $0.5-0.7$ mm (Minks et al. 1986 and Sarwar et al. 2014). Body color depending on the 
host plant was pale yellow to olive green or dark green. These were winged or wingless with long thin legs. The present investigation revealed that the mean body length of dark yellow colored adult was $0.22 \pm 0.005 \mathrm{~mm}$. This variation in size may be due to nutrient supplied by the host plant or other environmental factors (Shreth 1986).

A. gossypii showed dynamic interaction with C. esculenta. Natural population of this aphid showed significance differences in life history (viz. wild taro, $C$. esculenta esculenta and cultivated taro, C. esculenta antiquorum). Aphids from wild taro clones were bigger in size, mean relative growth rate, intrinsic rate of increase and production of offspring were larger in percentage and number from those of cultivated taro clones (Agarwala and Choudhury 2014). In the present study, development of $A$. gossypii was observed on cultivated varieties of $C$. esculenta which showed heavily infested on the erum plants. The growth rate was increasing day by day (Table 2). Probably it would be higher in percentage and number if the experiments were set in wild plants.

Some reports are available which show that $A$. gossypii is a polyphagous species. In addition to arum they infest other plants i.e. soyabean, brinjal, mustard in Bangladesh. However, the occurrence of this species on arum is the first report in Bangladesh. The A. gossypii reproduced very fast on the host plant C. esculenta in Dhaka. Within a week from the first appearance the host plant nymphal stages to such a high level that 280 of them occurred on per square centimeter of the leaf. Aphids in general are the rapid colonies have been described by Ghosh and Mitra (1983). They profusely reproduce on new young plants to increase their population as soon as possible at the cost of maximum utilization of energy resource in the host plant. This appears to be particularly true case of A. gossypii on the arum plants.

The maximum development of infestation occurred between mid-October and mid-November. The peak population lasted from last week of October to the first week of November. Margaritopoulos et al. (2009) noticed that the rapid population buildup of $A$. gossypii appears to involve parthenogenesis. However, it was not observed in this study in the arum aphids' population. It was also observed that abrupt increase of aphid population lasted from last week of October to mid-November. Their observations coincided to the present study. Further study is required.

There are several reports on the biological, chemical and cultural controls of A. gossypii in this subcontinent, but report on the mechanical control yet to be found (Sarwar et al. 2014). The mechanical control applied in the present work was effective to save the plant from the insect injury. In the present study it was observed that the highest $62 \%$ mortality occurred on the mechanically treated 
aphids. In Bangladesh, like other countries over the world, synthetic insecticides are being used as the major insect control practice neglecting their harmful effects on the animal kingdom as well as human populations. Growing up of the resistance of specific insecticides against their pests also should be under consideration (Begum et al. 2012).

\section{LITERATURE CITED}

AGARWALA, B.K. and CHOUDHURY, P.R. 2014. New host races of A. gossypii (Insecta: Hemiptera: Aphididae) from Northeast India. Current Science 107(7): 1172-1175.

BEGUM, M., KHAN, S., AHMED, S., RAHMAN, M. F. and KHAN, H.R. 2012. Susceptability of Culex quinquefasciatus and Aedes aegypti larvae to Basillus thurigiensis israelesis. Nuclear Science and Applications 21(1\&2): 41-45.

BLACKMAN, R.L. and EASTOP, V.F. 1994. Aphids on the world's trees: an identification and information guide. Cab International $1023 \mathrm{pp}$.

CONOVER, M.R. and DECKER, D. J. 1991. Wildlife damage to crops: perceptions of agricultural and wildlife professionals in 1957 and 1987. Wildlife Society Bulletine 19(1): 46-52.

GHOSH, M.R. and MITRA, A. 1983. Incidence pattern and population composition of Lipaphis erysimi (Kaltenbach) on mustard and radish. Pranikee 4: 43-51.

GRANETT, J., WALKER, M.A., KOCSIS, L. and OMER, A.D. 2001. Biology and management of grape phylloxera. Annual Review of Entomology 46(1): 387-412.

MARGARITOPOULOS, J.T., TZORTZI, M., ZARPAS, K.D. and TSISTSIPIS, J.A. 2009. Predominance of parthenogenetic reproduction in Aphis gossypii populations on summer crops and weeds in Greece. Bulletin of Insectology 62 (1): 15-20

McGAVIN, G. C. 1993. Bugs of the World. Blandford, London. 192 pp.

MINKS, A.K. and HARREWIJN, P. 1986. Aphids, their biology, natural enemies, and control. Volume 2A. Elsevier, New York, pp. 255-268.

SARWAR, M.K., AZAM, I., IRAM, N., IQBAL, W., RASHDA, A., ANWER, F., ATTA, R. and ALI, R. 2014. Cotton aphid Aphis aphis gossypii L. (Hemiptera : Aphididae) a challenging pest; biology and control strategies: A review. International J. Appl. Biol. Pharma. Technol. 5(1): 290-294.

SATAR, S., KERSTING, U. and UYGAN, N. 1999. Development and fecundity of Aphis gossypii Glover (Homoptera : Aphididae) on three Malvaceae hosts. Tropical Journal of Agriculture and Forestry 23: $637-643$.

SHRETH, 1986. Morphology and biology of the green apple aphids. Agricultural Research 5: 955-993.

TUKEY, JOHN 1949. Comparing individual means in the analysis of variance. Biometrics $\mathbf{5}(2)$ : 99-114. 